presented at meeting of the Midwestern Psychological Association, Cleveland, May 1972.

Forsman, R. Age differences in the effects of stimulus complexity and symmetrical form on choice reaction time and visual search performance. Journal of Experimental Child Psychology, 1967, 5, 406-429.

Gaines, $R$. The discriminability of form among young children. Journal of Experimental Child Psychology, 1969, 8, 418-431.

Gibson, E. J. Principles of perceptual learning and development. New York: Appleton-Century-Crofts, 1969.

Hohle, R. H. Component process latencies in reaction times of children and adults. In L. P. Lipsitt and C. C. Spiker (Eds.) Advances in child development and behavior. Vol. 3. New York: Academic Press, 1967. Pp. 225-261.

Krueger, L. E. Effect of stimulus frequency on speed of "same"."difference" judgments. In S. Kornblum (Ed.), Attention and performance, IV. New York: Academic Press, 1973. Pp. 497-506.
Leslie, R., \& Calfee, R. C. Visual search through word lists as a function of grade level, reading ability, and target repetition Perception \& Psychophysics, 1971, 10, 169-171.

Robinson, J. S. Familiar patterns are no easier to see than novel ones. American Journal of Psychology, 1969, 82, 513-522.

Spring, C. Perceptual speed in poor readers. Journal of Educational Psychology, 1971, 62, 492-500.

Surwillo, W. W. Human reaction time and period of the EEG in relation to development. Psychophysiology, 1971, 8, 468-482. Williams, J. D. The $\epsilon$ ffects of practice with controlled stimulus pairs on same-different judgments. Journal of Experimental Psychology, 1972, 96, 73-77.

(Received for publication September $14,1973$.

\title{
A test for both positive and negative response summation in the pigeon
}

\section{ROBERT J. HAMM and DONALD MELTZER Southern Illinois University at Carbondale Carbondale. Ill. 62901}

Four pigeons were trained to keypeck on a multiple variable interval-extinction schedule, in which different composite stimuli were associated with the variable interval and extinction schedules. The six composite stimuli used were compounds of houselight (on or off) and form (horizontal line, vertical line, or cross) on the response key. Composite stimuli were constructed in such a way that some components of houselight or form were more frequently associated with reinforcement or extinction. It was found that the composite stimulus formed of components most frequently associated with extinction controlled a lower response rate than other composite stimuli associated with extinction. However, the composite stimulus formed of components most frequently associated with reinforcement did not control a higher response rate than other reinforced stimuli.

Response summation refers to the increase (positive or additive summation) or decrease (negative or suppressive summation) in response probability observed when two independently conditioned stimuli are simultaneously presented. For example, in the case of positive summation, light and tone can be established as separate discriminative stimuli in the presence of which some response is reinforced. In the absence of either light or tone, no reinforcement is available. When light alone, tone alone, and the compound stimulus light plus tone are presented, more responses occur during the compound light plus tone than during either light or tone alone (e.g., Wolf, 1963; Weiss, 1964; Meltzer \& Freeman, 1970; Miller \& Ackley, 1970). This occurrence is labeled positive response summation. The interpretation applied to this phenomenon by Weiss (1972) is that the compound "light plus tone" is devoid of any $\mathrm{S} \Delta$ element and thus devoid of any low-rate controlling stimulus. It controls a higher rate than light alone and tone alone because light alone has the absence of light in common with $S \Delta$. Negative summation can also be demonstrated when positive reinforcement is used. For example, Weiss (1972) had described the performance of one rat which was conditioned to respond at high rates when neither light nor tone were present. Low rates were differentially reinforced when either light or tone or light plus tone was present. Response rate was lower during the compound stimulus than during either light or tone. Howerton (1972) reported a similar experiment in which rats were reinforced on a fixed-ratio schedule during tone and on a variable-interval (VI) schedule when light plus tone, neither light nor tone, or light alone was present. As predicted, Ss responded at the lowest rate during the light-alone condition. In these experiments, the simultaneous presentation of two stimuli, each of which controlled low response rates, caused the Ss to respond at a lower rate than when each stimulus was presented alone.

Although free-operant response summation has been frequently demonstrated (see Weiss, 1972), these demonstrations have occurred under quite specific conditions. First, only rats have been used as experimental Ss. Second, although both positive and negative summation have been obtained in appetitive situations, the same Ss have not been tested for both positive and negative summation within the same experimental session. In this experiment, we attempted to show both types of summation using pigeons as Ss.

\section{METHOD}

Subjects

Ss were four food-deprived pigeons which were maintained at 
Table 1

Stimulus Assignments

\begin{tabular}{|c|c|c|c|c|}
\hline \multirow{2}{*}{$\begin{array}{l}\text { Form } \\
\text { on Key }\end{array}$} & \multicolumn{2}{|c|}{$\begin{array}{l}\text { Ss } 1 \text { and } 2 \\
\text { Houselight }\end{array}$} & \multicolumn{2}{|c|}{$\begin{array}{l}\text { Ss } 3 \text { and } 4 \\
\text { Hou selight }\end{array}$} \\
\hline & On & Off & On & Off \\
\hline Cross & $\mathrm{S}^{N \text { test }}$ & $\mathrm{S}^{\Delta 2}$ & $\mathrm{~S}^{\text {Ptest }}$ & $\mathrm{S}^{\mathrm{D} 2}$ \\
\hline Horizontal & $\mathrm{s}^{\Delta 1}$ & SD1 & SD1 & $\mathrm{S}^{\Delta 1}$ \\
\hline Vertical & $\mathrm{S}^{\mathrm{D} 2}$ & $S^{P \text { test }}$ & $\mathrm{S}^{\Delta 2}$ & $\mathrm{~S}^{\mathrm{N}}$ test \\
\hline
\end{tabular}

$80 \%$ to $85 \%$ of their free-feeding weights. Water and grit were continuously available in the $S$ 's home cage. After the experimental session, Ss were given additional feedings to maintain each $S$ at its prescribed weight. Experimental sessions were scheduled 5 days a week.

\section{Apparatus}

The experimental chamber was manufactured by BRS Foringer (Model PH-002) with interior diminsions of $50 \times 35 \times$ $25 \mathrm{~cm}$. The front panel of the chamber contained a response key $(3 \mathrm{~cm}$ in diam), located $25 \mathrm{~cm}$ above the grid floor and $7.5 \mathrm{~cm}$ from the left wall, which required a force of $0.18 \mathrm{~N}$ for activation. The food hopper was located behind a $5 \times 4 \mathrm{~cm}$ opening $7 \mathrm{~cm}$ above the grid floor and centered on the midline of the stimulus panel. Two lamps (GE 757), behind a $7.5 \times$ $35 \mathrm{~cm}$ piece of white Plexiglas, were mounted over the stimulus panel and served as a houselight. The intensity of the houselight was $15.8 \mathrm{fL}$, as measured by a SEI photometer. The interior of the chamber was painted a flat white. Ventilation and a masking noise were provided by a fan.

The stimuli were projected onto the key from the rear of the panel by an Industrial Electronics engineer's one-plane digital readout (Model 10-0229-1820-L). The readout projected one of three forms (cross, vertical line, or horizontal line), which were constructed by a $0.2-\mathrm{cm}$-wide white line projected on a black background. Stimulus compounding was achieved by projecting one form on the response key and having the houselight either on or off. Thus, the stimuli used were compounds of houselight on or off and cross $(\mathrm{C})$, vertical line (V), or horizontal line (H) on the response key. For example, the stimulus abbreviated as $\mathrm{C}+\mathrm{L}$ represents a cross on the response key and the houselight on. The stimulus $\mathrm{V}+\overline{\mathrm{L}}$ represents a vertical line on the respons key and the houselight off. The other stimuli used were $\mathrm{C}+\overline{\mathrm{L}}$ $\mathrm{V}+\mathrm{L}, \mathrm{H}+\mathrm{L}$, and $\mathrm{H}+\overline{\mathrm{L}}$.

\section{Procedure}

\section{Training}

All stimuli were presented in a random order for a 30 -sec duration. During a session, each stimulus was presented four times, with a 5-sec blackout between all stimulus presentations. Responses during all stimuli were continuously reinforced for four sessions. During the next four sessions, the reinforcement schedule was changed to variable-interval 15-sec (VI 15-sec). Finally, the stimulus duration was increased to $2 \mathrm{~min}$ and responses were reinforced on a VI 1-min schedule. Eighteen sessions were conducted with a VI 1-min schedule of reinforcement in effect during each stimulus to establish stable response rates during all stimuli.

\section{Testing}

In order to test for response summation, the schedule of reinforcement was changed to multiple VI 1-min extinction. Three stimuli ( $S^{D 1}, S^{D 2}$, and $\left.S^{P t e s t}\right)$ were separately correlated with the VI component of the multiple schedule. $S^{\Delta \mathbf{1}}, S^{\Delta \mathbf{2}}$, and SNtest were correlated with the extinction component of the multiple schedule. See Table 1 for the specific stimuli associated with each component schedule for each $\mathrm{S}$. As can be seen from the table, the bottom two rows for $S 1$ and $S 2$ and the top two rows for S3 and S4 are similar to the stimulus arrangements used to investigate positive summation, since $S^{P \text { test }}$ is devoid of any form component of $S \Delta 1$. Likewise, the top two rows for $S 1$ and $\mathrm{S} 2$ and bottom two rows for S3 and S4 are similar to those designs used to investigate negative summation, since $\mathrm{S}^{\mathrm{N}}$ test has no form component in common with $\mathrm{S}^{\mathrm{D} 1}$. However, the situation differs from the usual procedure in response summation studies, since neither the light nor the no-light component of the compound stimuli is associated exclusively with either the $\mathbf{S D}_{\mathbf{S}}$ or the $\mathbf{S} \boldsymbol{\Delta}_{\mathbf{S}}$. Thus, for $\mathbf{S} 1$ and $\mathbf{S} 2$ there was a 0.67 probability that the extinction schedule was in effect when the light was on and a 0.67 probability that the VI schedule was in effect when the light was off. The probabilistic relation between the on-off condition of the light and the schedule in effect was reversed for S3 and S4.

Positive summation was expected to occur when $\mathrm{S}^{\text {Ptest }}$ was presented, since it was a compound of a form stimulus which was present only during $S^{D}$ and a light condition during which $\mathrm{S}^{D}$ was twice as probable as $\mathrm{S}^{\Delta}$. By the same token, negative summation was expected when $S^{N \text { test }}$ was presented, since it was a compound of a form stimulus which was present only during $S^{\Delta}$ and a light condition during which $S^{\Delta}$ was twice as probable as $S^{\mathbf{D}}$.

The stimuli were presented in a quasirandom order. The restriction imposed on the sequence was that no more than two extinction-associated stimuli or two VI-associated stimuli occurred consecutively. As in the training phase, each stimulus was presented four times during each session and remained on for $2 \mathrm{~min}$ during each presentation. Thirty sessions were conducted.

\section{RESULTS}

Mean response rates during each stimulus were computed in blocks of three sessions for each S. Since response rates during the $S^{\Delta}$ S had such a large range, it was necessary to plot response rate along a logarithmic scale for each $\mathrm{S}$, as shown in Fig. 1. The first five blocks of sessions were assumed to represent the acquisition of the discrimination between the stimuli associated with the multiple schedule. The last five blocks of sessions were of primary concern, since they were more analogous to steady-state performance, during which response summation has usually been demonstrated. Figure 1 shows that over the last five blocks of sessions, $\mathrm{S}^{\mathrm{N} \text { test }}$ controlled the lowest response rate of all $\mathrm{S}^{\Delta} \mathrm{S}$ over all blocks for S2, S3, and S4. For S1, SN test controlled the lowest response rate on three of the last five blocks. An analysis of variance was performed for the last five session blocks in which each S's response rate during $\mathrm{S}^{\mathrm{N}}$ test was compared with the lowest response rate of the same $S$ in either of the other two $S \Delta$ s. For instance, $S 2$ had response rates during $S^{\Delta} 2$ included in the analysis for four of the five blocks of sessions. However, during the ninth session block, S2 responded at a lower rate during $S^{\Delta 1}$ than during $S^{\Delta \mathbf{2}}$, and so in that block, rate during $\mathrm{S}^{N}$ test was compared to rate during $S^{\Delta 1}$. The results showed that the Ss responded at a significantly lower rate during $S^{N}$ test than during the $\mathrm{S}^{\Delta}$ controlling the next lowest rate $(\mathrm{F}=$ $21.79, \mathrm{df}=1 / 3, \mathrm{p}<.02)$. Although $\mathrm{S}^{\mathrm{N}}$ test consistently controlled the lowest response rate, the difference in response rate between $S^{N}$ test and the next lowest $S^{\Delta}$ was small in magnitude (generally about 1.0 responses/min) at the terminal level of performance. In 
addition to $\mathrm{S}^{\mathrm{N}}$ test controlling the lowest response rate, $S^{\Delta 1}$ consistently controlled the highest $S^{\Delta}$ response rate for S3 and S4. For S1 and S2, S $\Delta 1$ controlled the highest $S^{\Delta}$ rate on four of the last five blocks of sessions. The magnitude of the difference in response rate between $S^{\Delta} \mathbf{1}$ and the next highest $S^{\Delta}$ rate was in the range of greater than 10 responses/min for all Ss except S2.

Figure 2 shows the mean response rate to three $\mathbf{S}_{\mathbf{S}}$ over the 10 blocks of summation testing. Here again, the last 5 blocks are of primary concern. $S^{\text {P test }}$ consistently controlled the highest SD rate only for S2. The other Ss exhibited no consistent trends with regard to $S^{P}$ test. An analysis of the stimuli controlling the two highest $S^{D}$ rates for each $S$ over the last 5 blocks yielded no significant differences.

\section{DISCUSSION}

It is not clear why we were unable to show evidence of positive summation while the pigeons did develop negative summation. A number of other unpublished experiments in our laboratory using compounds of color and form stimuli projected on the response key have also failed to produce positive summation in the pigeon. This suggests that either the pigeon does not respond to compounds of separately conditioned SD in the same way as the rat or that stimuli which are presented at a specific locus do not produce positive response summation in the same way that more diffuse stimuli, such as ambient light or tone, do. Neither of these hypotheses seems easily compatible with the development of negative summation. There is one

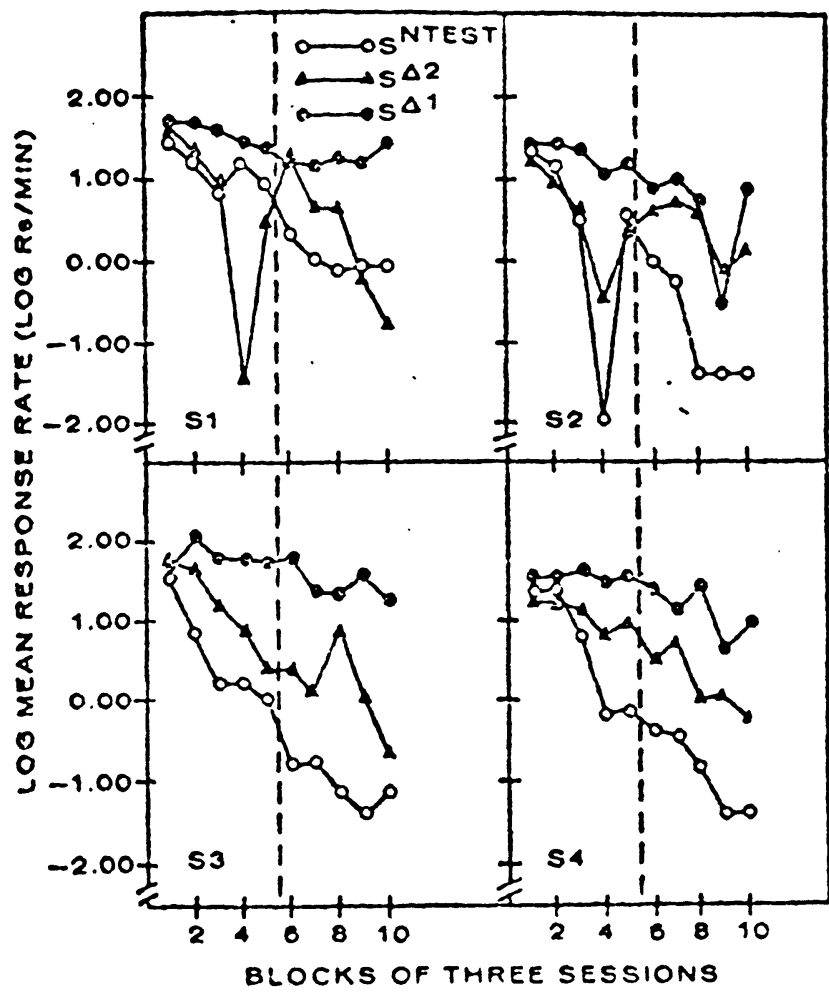

Fig. 1. The logarithm of the mean response rate of the four Ss during each of the stimuli are shown above. An extinction schedule was in effect during each stimulus. The last five blocks of sessions represent steady-state performance.

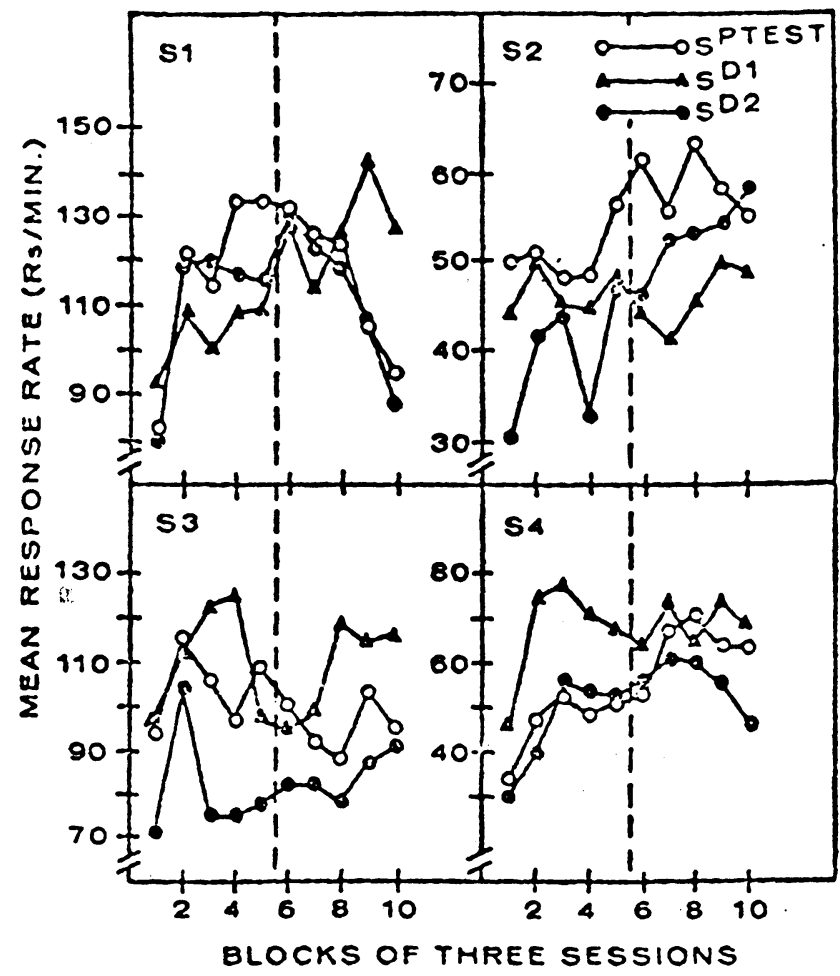

Fig. 2. The response rate during the VI-associated stimuli $\left(S^{\left.D_{S}\right)}\right.$ are shown for each $S$ over blocks of three sessions. The last five blocks represent steady-state performance.

possible explanation which deserves mention. The response rates controlled by $S^{D 1}$ and $S^{\Delta 1}$ are critical for the development of negative and positive summation, respectively. In order for negative summation to be obtained, $\mathrm{S}^{\mathrm{D} 1}$ must control a higher response rate than either $S^{\Delta \mathbf{1}}$ or $S \Delta \mathbf{2}$. Similarly, for positive summation to be demonstrated, $\mathrm{S} \Delta \mathbf{1}$ must control a lower response rate than either $S^{D 1}$ or $S$ D2 . Both these conditions are met in this experiment, but the magnitude of the difference in response rates necessary to produce positive and negative summation may be different. Thus, the rate controlled by $\mathrm{S}^{\mathrm{D} 1}$ may be high enough in relation to $S^{\Delta 1}$ and $S^{\Delta \mathbf{2}}$ to produce negative summation, while the rate controlled by $S \Delta 1$ may not be low enough in relation to $S^{D 1}$ and $S^{D 2}$ to produce a positive summation. This hypothesis has some support in that $\mathrm{S} 2$ was the only $S$ for which $S^{\Delta 1}$ controlled a low rate less than 10 responses/min) and was also the only $S$ to demonstrate positive summation. In the final analysis, then, the absence of positive summation in this experiment may just be a matter of $S^{\Delta \mathbf{1}}$ not controlling a low enough response rate.

\section{REFERENCES}

Howerton, D. L. Suppressive summation in an appetitive free-operant situation. Paper presented at Midwestern Psvchological Association meetings, Cleveland, May 1972.

Meltzer, D., \& Freeman, B. J. Maintenance of response summation under conditions of minimum stimulus intensity. Psychonomic Science, 1971, 22, 287-289.

Miller, L. \& Ackley, R. Summation of responding maintained by fixed-interval schedules. Journal of the Experimental Analysis of Behavior, 1970,13,199-203.

Weiss, S. J. Summation of response strengths instrumentally conditioned to stimuli in different sensory modalities. Journal of Experimental Psychology, 1964, 88, 151-155.

Weiss, S. J Stimulus compounding in free-operant and classical conditioning: A review and analysis. Psychological Bulletin. 1972. 78, 189-208.

Wolf, M. M. Some effects of combined $S^{D}$. Journal of the Experimental Analysis of Behavior, 1963,6, 343-347.

(Received for publication September 12. 1973.) 